\title{
On the Evolution and Practice of Research Hot Spots of China's Physical Education and Training in the New Era
}

\author{
Yao Dong \\ Minjiang University, Fujian, China, 350108
}

Keywords: physical education; training; hot spot; evolution

Abstract: With the continuous development and reform of the times, it is an important task for the study of physical education and training in the new era to promote the students' overall physical and mental health development and improve their overall physical fitness. And this is also an important reason for improving students' physical fitness. At present, there are many problems for students' physical development and optimization. Among them, students' physical development function, form, and fit with students' physical fitness are the most important aspects. This article analyzes the development of the research focus of China's sports education and training in the new era

\section{Introduction}

For students, their psychological level and social adaptation and development ability have long been weak. By analyzing the student's physical examination data, potential problems can be unearthed from this, and a more comprehensive understanding and observation of the overall physical development and growth of the student can be provided, providing a reliable reference for the school, society, and family. The data allows managers to conduct in-depth investigations and decision making on student health development decisions. Therefore, the author will conduct an overall survey of students in our country to fully understand their physical features and development status, sum up experiences and discover problems.

\section{Status Quo of Research on China's Physical Education and Training in the New Era}

\subsection{Influence of Physical Education on Students}

Physical exercise refers to a kind of physical exercise with the purpose of using various physical exercises to develop the body, promote health, regulate spirit, enrich cultural life, and control leisure time.

Tab.1 Current high school students' extracurricular physical exercise time $(\mathrm{N}=579)$

\begin{tabular}{cccccc}
\hline Exercise time (min) & $<\mathbf{3 0}$ & $\mathbf{3 0 - 6 0}$ & $\mathbf{3 6 0}$ & $\mathbf{X}^{\mathbf{2}}$ & $\mathbf{P}$ \\
\hline Number of persons & 319 & 169 & 91 & 232.624 & 0.000 \\
Percentage (\%) & 55.1 & $\mathbf{2 9 . 2}$ & 15.7 & & \\
\hline
\end{tabular}

The father of the modern Olympics, Coubertin, praised him with enthusiasm in his famous song 
"Song of Sports": Sports is "courage" and "fun". It can make people "happy in heart" and "open minded". , "Structure is clearer," "It helps people who are sad to break up and relax, and make happy people live more sweetly." A large number of practical experiences and scientific experiments have proved that physical exercise is the most active and effective method for improving health (including mental health), enhancing physical fitness, and developing the body. It cannot be replaced by any other activity.

\subsection{The Role of Physical Education and Training}

Those who have been engaged in physical exercise for a long time are full of self-confidence, because he understands his physical condition better and believes that his body can guarantee the realization of the goal. From a healthy body, what we can feel is the physical appearance of beauty? The constant toughness, dexterity, and self-confidence that have flowed out from time to time have enabled us to feel the vigorous and vigorous vitality. Sports are not a survival skill, nor are it the means by which most people make a living, but it embodies the value of life.

\section{The Evolution of Research Hotspots of Physical Education and Training in the New Era}

According to the student's physical fitness monitoring results, the author found that the development and the form of the students in different classes showed a skewed distribution pattern. In the high school student group, the proportion of overweight groups was higher than in previous grades, but the school's high school students the figures for height and weight are higher than those for China's average age. The overall physical fitness is in the middle ranks. The author analyzes its problems mainly from the following aspects:

\subsection{The sophomore group has a relatively high proportion of overweight}

This aspect is a factor of regional inheritance. On the other hand, the daily life styles of people in the area are closely related. In recent years, the economy in the surrounding areas of the school has developed rapidly, and the lifestyle of the surrounding people has also undergone enormous changes. Some high-energy, high-fat diets are gaining popularity, while some healthy fruits and vegetables are poorly ingested. This is especially true for the office worker's parents. This kind of family situation is often more plentiful at dinner time, but on the other hand it is more contrary to the law of energy consumption.

\subsection{Parents attach too much importance to their children's studies and neglect their fitness}

From the above survey, it can be seen that the physical training students' body size and the shape of their body shape still occupy the majority, and the average height of the students is also higher than the area. Some of the students in this school are from rural areas. Their shape is still relatively good, and it is relatively easy to have potential talents in sports. At present, parents in society pay too much attention to their children's studies. Few parents will lead children to fitness, so their physical fitness will not be very good.

\subsection{Parents and students have a healthy blind spot}

For many years, all areas in our country have paid more attention to the health education of students. Therefore, our country's senior high school students are more rigorous about their daily health and hygiene knowledge. But this is where the parents come to an abrupt end. Parents have a 
lot of problems with the health of the blind, and because parents are busy with their daily work, it is difficult to timely take care of the child's potential common diseases.

Tab.2 Table of Physical Exercises for Senior High School Students (N=579)

\begin{tabular}{cccccccc}
\hline $\begin{array}{c}\text { Frequency of motion } \\
\text { (times/weeks) }\end{array}$ & $\mathbf{0}$ & $\mathbf{1}$ & $\mathbf{2}$ & $\mathbf{3}$ & $\mathbf{> 3}$ & $\mathbf{X}^{\mathbf{2}}$ & $\mathbf{P}$ \\
\hline Number of persons & 24 & 298 & 128 & 102 & 27 & 184.796 & 0.000 \\
Percentage (\%) & 4.1 & 51.4 & 22.1 & 17.6 & 4.6 & & \\
\hline
\end{tabular}

\subsection{There are many teachers' courses and they do not pay attention to students' physique}

The average number of physical education teachers in the school each week is about 18 classes. In addition to this, some teachers are also working in other forms of part-time jobs. High-school full-time sports teachers are too poor. At the same time, teachers tend to be aging. There are very few students who graduate from physical education colleges to become professional teachers. There have also been phenomena in which the class teacher and other teachers have taken classes in physical education. Because these teachers are not professional sports talents and have little knowledge of sports knowledge, they naturally do not have a good development for students' overall physical fitness.

\subsection{The negative effect of excessive physical exercise on mental health}

Only proper physical exercise can promote mental health. On the contrary, if the methods and means used are unscientific, it will not only damage physical health, but also bring negative impact on mental health. Its main manifestations are psychological exhaustion and exercise dependence. Psychological exhaustion is a kind of exhaustive psychophysiological reaction that exercisers produce due to long-term insurmountable exercise stress during exercise, which is a kind of exercise psychological symptoms. This symptom will not only damage the mental health of exercisers, but may also directly lead to their withdrawal from exercise.

\section{Insufficiency and Practice of Sports Training Research in the New Period}

\subsection{The theoretical system of exercise psychology has not been perfected}

Exercise Psychology is an applied subject that develops with the development of sports psychology. It studies various psychological issues in the field of fitness activities, but the content of studies specific to exercise psychology is different from the current one. According to various domestic research results, the content of exercise psychology is mostly taken from the disciplines of sports psychology and educational psychology, and the arguments are inconsistent.

\subsection{Exercise Psychology Discipline High Quality Research Team Construction}

Strengthening the construction of discipline research teams is a key factor affecting the development of disciplines. In accordance with the theoretical system and research content of exercise psychology to form a research team, the research team of exercise psychology needs to be composed of the following professional training researchers: sociology, psychology, pedagogy, kinematics, statistics, sports, etc. Based on this, we jointly developed specific experimental plans and procedures. And use the card square test formula to analyze the results of the reform attempt: 


$$
\chi^{2}=\sum \frac{\left(f_{0}-f_{e}\right)^{2}}{f_{e}} \sim \chi^{2}
$$

Exercise psychology is an interdisciplinary group. From a single subject perspective, the study of the sports institute is limited by disciplines and cannot obtain a comprehensive and systematic understanding.

\subsection{Lack of innovation in research methods and methods}

At present, there is relatively little research on sports scientific research methods. Exercise psychology has no independent systematic research methods. Most of the research results still fully apply research methods of general psychology, educational psychology, and sports psychology.

\subsection{Backwardness of curriculum system and teaching materials construction}

At present, China has a relatively complete sports psychology and sports psychology teaching material system, but there is not a physical exercise psychology, which brings inconvenience to the training of physical exercise psychology and the training of physical exercise instructors. The construction of school textbooks has been lagging behind. Looking at the research results of Chinese scholars in the field of exercise psychology in the past decade, the progress is comprehensive, and the overall level of research has made encouraging progress.

\section{Summary}

At the same time, we should also be soberly aware that there are still many problems in the current research in this area: mainly due to the limitations of research methods, resulting in the urgent need to improve the quality and level of research. Tension is the psychological research issue mentioned in 2004: There is no research hypothesis, there are too many hypotheses, the statistical method is too simple, and the format for writing is not standardized. It is still basically consistent. In order to further improve the research level, we need to pay attention to Tenshui's five suggestions: emphasis on the theoretical hypothesis, the pursuit of causality, the exploration of the third variable, the introduction of multivariate statistics, and the use of advanced technologies.

\section{References}

[1] Kreemer C. Absolute plate motions constrained by shear wave splitting orientations with implications for hot spot motions and mantle flow[J]. Journal of Geophysical Research Solid Earth, 2009, 114(B10):-.

[2] Margulies E H, Cooper G M, Asimenos G, et al. Analyses of deep mammalian sequence alignments and constraint predictions for 1\% of the human genome[J]. Genome Research, 2007, 17(6):760.

[3] Hudman R C, Jacob D J, Turquety S, et al. Surface and lightning sources of nitrogen oxides over the United States: Magnitudes, chemical evolution, and outflow[J]. Journal of Geophysical Research Atmospheres, 2007, 112(D12):271-283. 